УДК 330

\title{
ПРОГНОЗ ПОКАЗАТЕЛЕЙ ФИНАНСОВОГО СОСТОЯНИЯ И ДИАГНОСТИКА ВОЗМОЖНОГО БАНКРОТСТВА СЕЛЬСКОХОЗЯЙСТВЕННОГО ПРЕДПРИЯТИЯ
}

\author{
Колесова Ксения Дмитриевна \\ студент \\ Научный руководитель: Навдаева Светлана Николаевна \\ к.э.н., доцент \\ ФГБОУ ВО «Нижегородская государственная \\ сельскохозяйственная академия»
}

Аннотация: B статье проанализировано финансовое состояние сельскохозяйственного предприятия. Выявлены за 2012-2019 гг. тенденции в изменении показателей. На основе фактических данных сделан прогноз показателей на 2021-2023 гг.

Проведение данного анализа и полученные результаты служат основой принятия эффективных управленческих решений руководством предприятия.

Ключевые слова: финансовое состояние, прогноз, сельскохозяйственное предприятие, тенденция, тренд.

\section{FORECAST OF FINANCIAL CONDITION INDICATORS AND DIAGNOSTICS OF POSSIBLE BANKRUPTCY OF AN AGRICULTURAL ENTERPRISE}

Kolesova Xenia Dmitrievna Scientific adviser: Navdaeva Svetlana Nikolaevna

\begin{abstract}
The article analyzes the financial condition of an agricultural enterprise. Trends in changes in indicators were identified for 2012-2019. Based on the actual data, the forecast of indicators for 2021-2023 is made.

Conducting this analysis and the results obtained serve as the basis for making effective management decisions by the company's management.

Key words: financial condition, forecast, agricultural enterprise, trend, trend.
\end{abstract}


Актуальность задач, связанных с прогнозированием финансового состояния предприятия, отражена в одном из используемых определений финансового анализа, согласно которому, финансовый анализ представляет собой процесс, основанный на изучении данных о финансовом состоянии предприятия и результатах его деятельности в прошлом с целью оценки будущих условий и результатов деятельности. Таким образом, главной задачей финансового анализа является снижение неизбежной неопределенности, связанной с принятием экономических решений, ориентированных в будущее. При таком подходе финансовый анализ может использоваться как инструмент обоснования краткосрочных и долгосрочных экономических решений, целесообразности инвестиций, как средство оценки мастерства и качества управления; как способ прогнозирования будущих финансовых результатов. Финансовое прогнозирование позволяет в значительной степени улучшить управление предприятием за счет обеспечения координации всех факторов производства и реализации, взаимосвязи деятельности всех подразделений, и распределения ответственности.

На рисунках 1-9 представлены результаты трендового анализа показателей финансового состояния сельскохозяйственного предприятия.

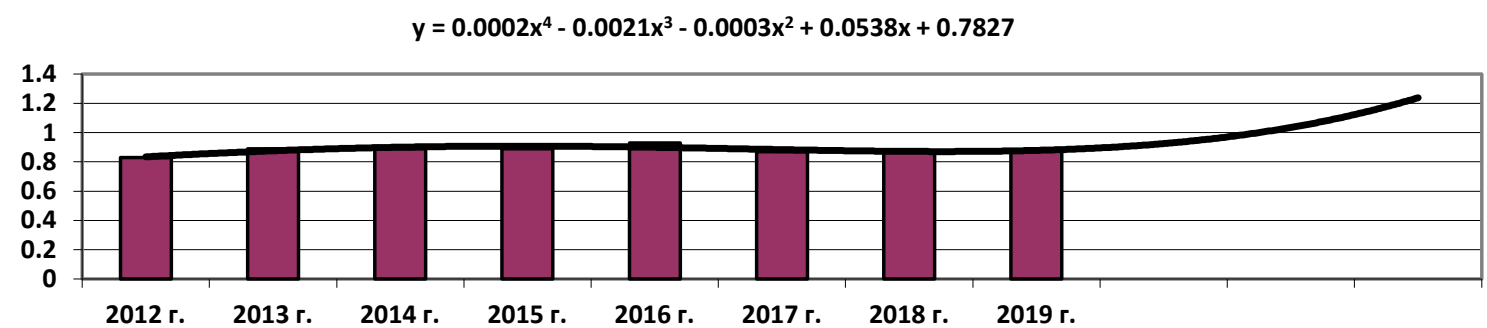

$\square$ Коэффициент автономии Р Poly. (Коэффициент автономии)

\section{Рис. 1. Динамика и прогноз коэффициента автономии в СХПК}

Можно говорить об усилении финансовой автономии, если коэффициент имеет положительный тренд. Рост коэффициента автономии свидетельствует о том, что организация все больше полагается на собственные источники финансирования. 

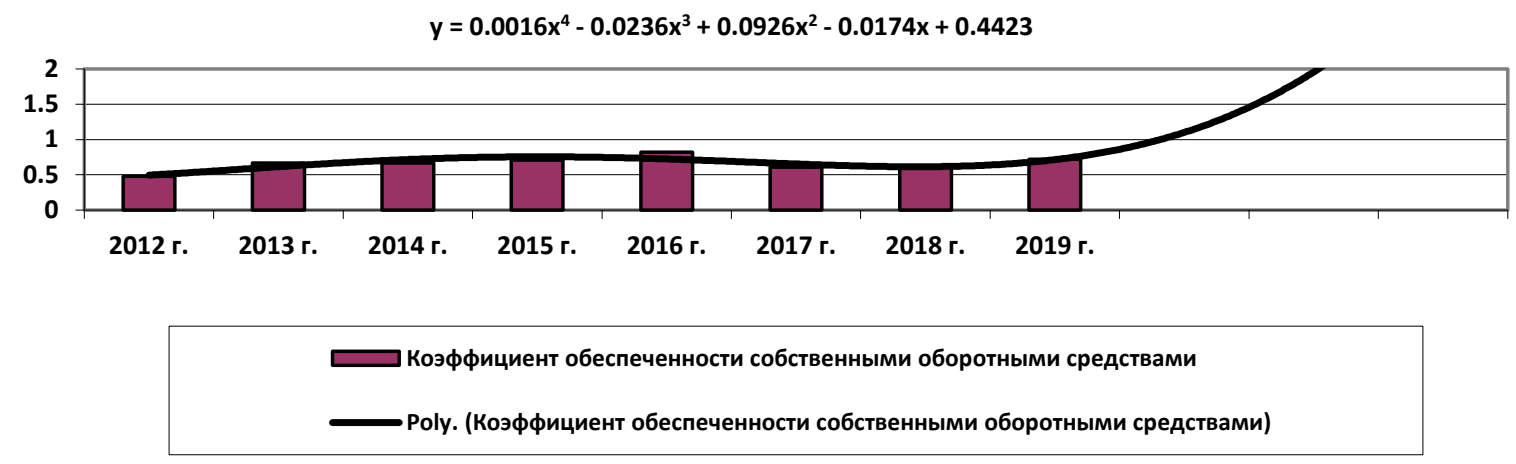

\section{Рис. 2. Динамика и прогноз коэффициента обеспеченности собственными оборотными средствами в СХПК}

Если коэффициент обеспеченности собственными оборотными средствами растет, то это говорит о том, что увеличивается финансовая устойчивость предприятия, увеличивается собственный капитал предприятия, уменьшается кредиторская задолженность.

Развитие экономики невозможно без внедрения новых проектов, для разработки и выполнения которых необходимо привлечение инвестиций. В то же время инвестирование в проекты всегда сопряжено с рисками, их влияние особенно велико в периоды кризисов.

На рис. 3 отражена определенная стабильность коэффициента покрытия инвестиций на предприятии.

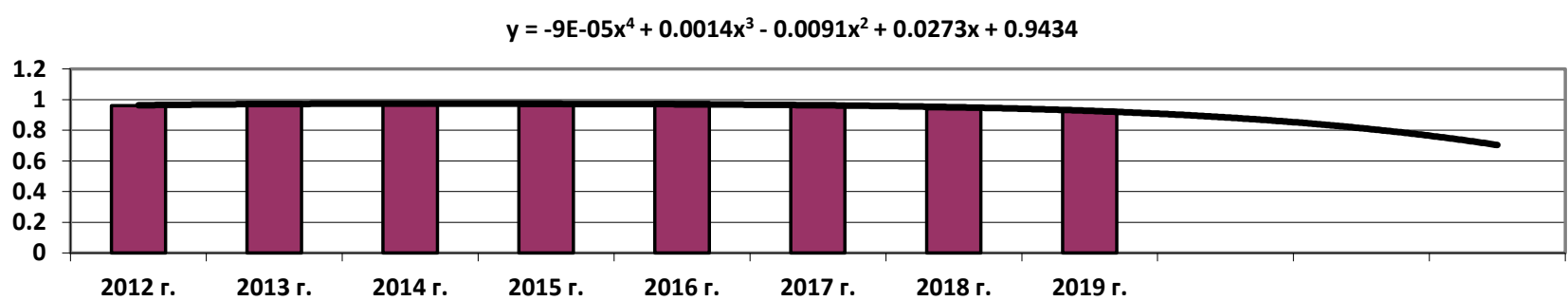

Коэффициент покрытия инвестиций $\quad$ Poly. (Коэффициент покрытия инвестиций)

Рис. 3. Динамика и прогноз коэффициента покрытия инвестиций в СХПК

С точки зрения инвестиционного процесса, особое значение имеет величина покрытия вложений, расчет при этом позволяет принять эффективные управленческие решения, как для самого проекта (предприятия), так и для направления инвестиций в наиболее выгодном направлении. 
На рис. 4 представлен прогноз коэффициента текущей ликвидности предприятия. Ликвидность предприятия варьирует, но все показатели выше нормативного значения.

$y=0.0885 x^{5}-1.9925 x^{4}+16.582 x^{3}-62.828 x^{2}+106.03 x-49.203$

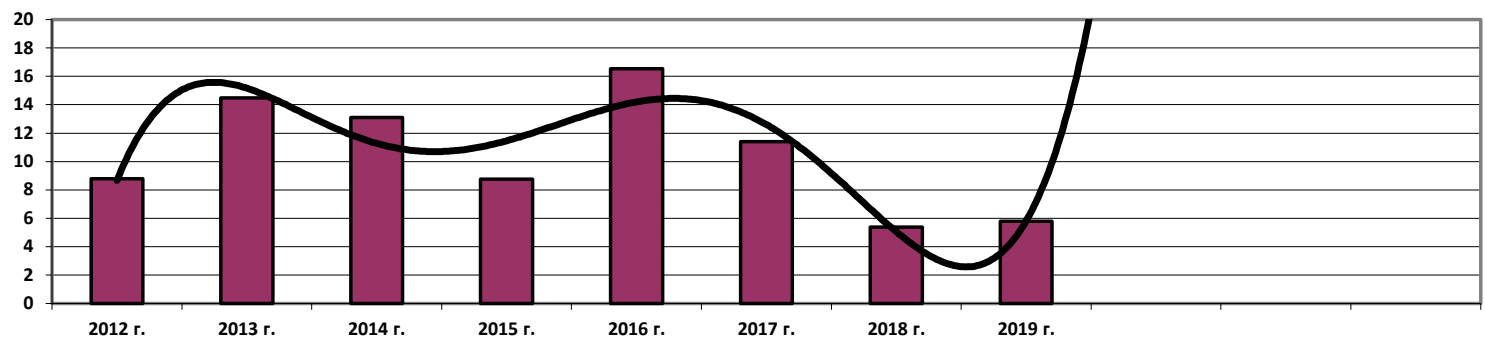

Коэффициент текүщнй ликвидности

— Poly. (Коэффициент текущнй ликвидности)

\section{Рис. 4. Динамика и прогноз коэффициента текущей ликвидности в СХПК}

С другой стороны, завышенный показатель текущей ликвидности часто говорит о недостаточно активном использовании оборотных активов и ограничении доступа к краткосрочному кредитованию.

Также рост коэффициента текущей ликвидности может произойти из-за таких негативных факторов как: ужесточение условий расчётов с контрагентами-поставщиками, чрезмерное ослабление требований к покупателям по срокам расчётов (фактически, безвозмездное кредитование покупателей), увеличение на складах остатков сырья и материалов.

Варьируют в динамике и коэффициент быстрой ликвидности (рис. 5) и коэффициент абсолютной ликвидности (рис.6).

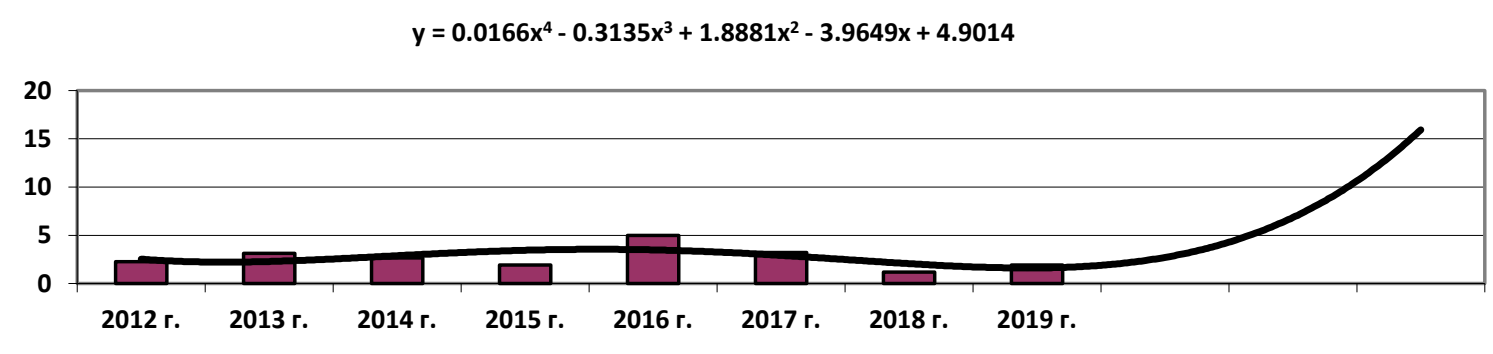

$\square$ Коэффициент быстрой ликвидности

—Poly. (Коэффициент быстрой ликвидности)

Рис. 5. Динамика и прогноз коэффициента быстрой ликвидности в СХПК 
Финансовое положение компании признается хорошим, когда коэффициент абсолютной ликвидности больше или равен 0,15. Иными словами не менее 15\% краткосрочных обязательств должно быть обеспечено денежными средствами, их эквивалентами, и другими абсолютно ликвидными активами.

$y=0.0109 x^{5}-0.2407 x^{4}+1.9737 x^{3}-7.3126 x^{2}+11.773 x-5.7525$

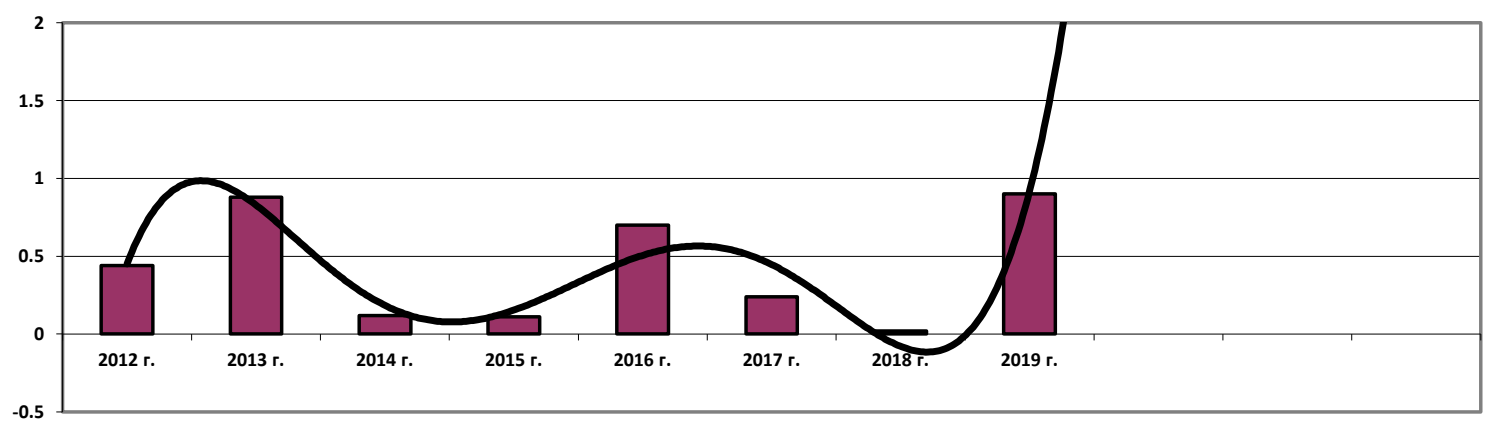

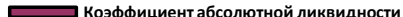

Poly. (Коэффициент абсолютной ликвидности)

Рис. 6. Динамика и прогноз коэффициента абсолютной ликвидности в СХПК

Чаще всего рост коэффициента абсолютной ликвидности говорит об улучшении финансового положения предприятия. В такой ситуации оно становится более финансово-устойчивым и платежеспособным. Снижение коэффициента обычно означает противоположное: финансовое положение компании ухудшается.

Иногда снижение коэффициента абсолютной ликвидности может не столько говорить об ухудшении платежеспособности и ликвидности компании, сколько о повышении эффективности использования активов. Чаще всего это происходит тогда, когда значение коэффициента значительно больше норматива.

Рентабельность продаж - один из основных финансовых показателей для оценки эффективности работы предприятия. Динамика показателя отражена на рис. 7. 
$y=-0.0001 x^{4}+0.0029 x^{3}-0.0156 x^{2}-0.0063 x+0.378$

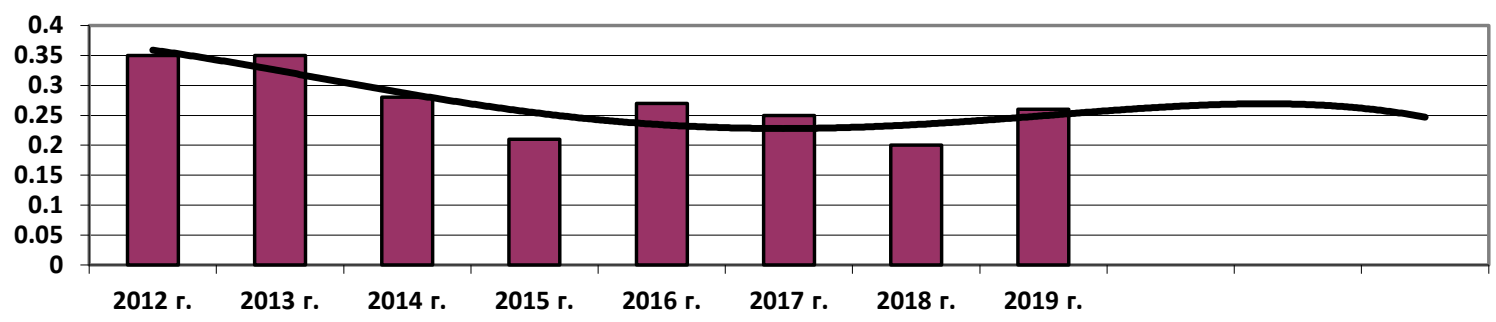

Рис. 7. Динамика и прогноз коэффициента рентабельности продаж в СХПК

При анализе рентабельности продаж, можно отметить определенную цикличность, что обусловлено цикличностью урожайности сельскохозяйственных культур и, следовательно, изменениями цен на продукцию.

$y=0.0005 x^{4}-0.0086 x^{3}+0.0535 x^{2}-0.142 x+0.2704$

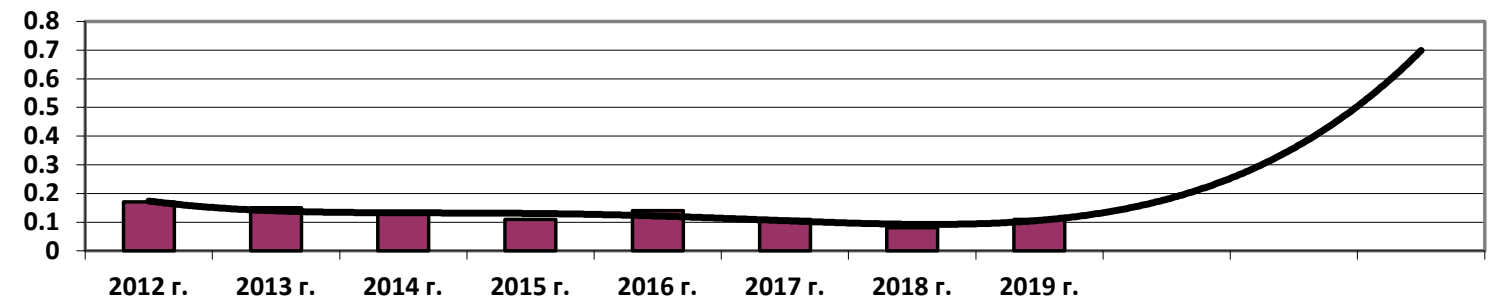

$\square$ Коэффициент рентабельности активов — Poly. (Коэффициент рентабельности активов)

Рис. 8. Динамика и прогноз коэффициента рентабельности активов в СХПК

Рентабельность активов предприятия имеет тенденцию роста, как и рентабельность собственного капитала (рис.9). 

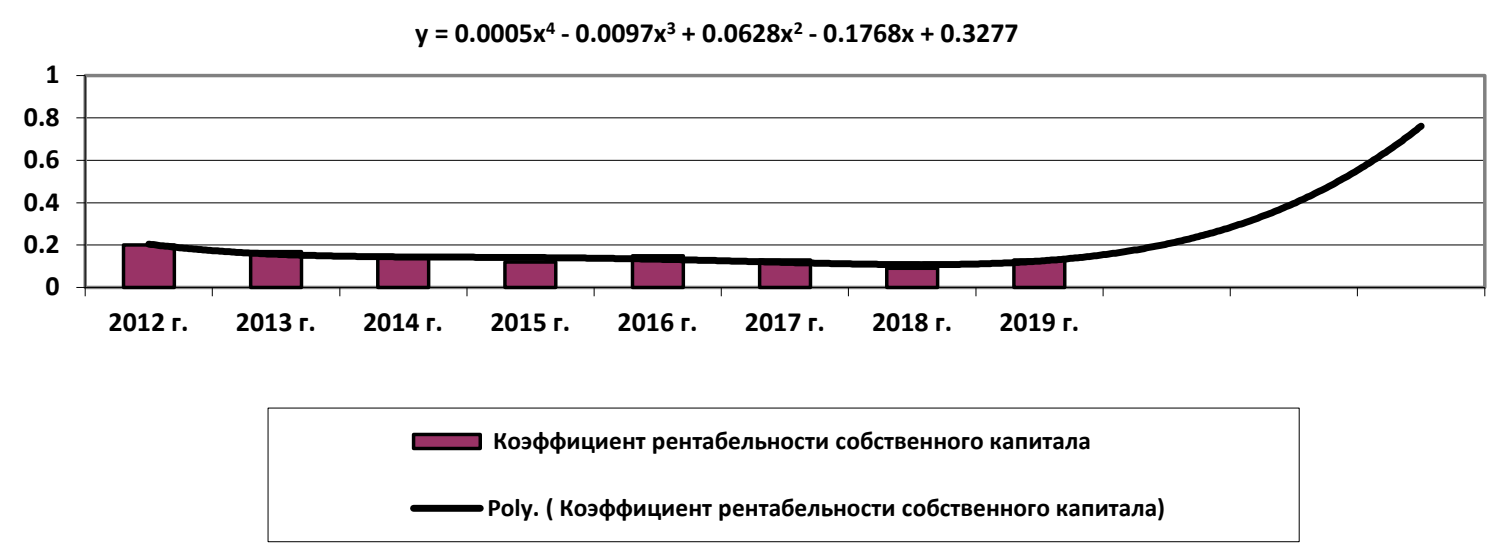

\section{Рис. 9. Динамика и прогноз коэффициента рентабельности собственного капитала в СХПК}

В перспективе ожидается рост практически всех показателей, кроме рентабельности продаж и коэффициента покрытия инвестиций.

Для прогнозирования можно использовать функцию ТЕНДЕНЦИЯ в Excel. C eе помощью рассчитывают будущие значения изучаемого показателя в соответствии с линейным трендом. Используя метод наименьших квадратов, функция аппроксимирует прямой линией диапазоны известных значений у и известных значений х. Прогнозирует значения у, соответствующие данной линии, для новых значений х.

На основе данных за 2017-2019 гг. спрогнозируем показатели финансового состояния СХПК, используя данную функцию. Результаты представлены в таблице 1 .

Таблица 1

Прогноз показателей финансового состояния предприятия

\begin{tabular}{|c|c|c|c|c|c|c|}
\hline \multirow{2}{*}{ Показатели } & \multicolumn{3}{|c|}{ Фактические значения } & \multicolumn{3}{|c|}{ Прогноз } \\
\hline & 2017 г. & 2018 г. & 2019 г. & $2021 \Gamma$. & 2022 г. & 2023 г. \\
\hline \multicolumn{7}{|l|}{ 1. Финансовая устойчивость } \\
\hline $\begin{array}{l}\text { 1.1. Коэффициент } \\
\text { автономии (финансовой } \\
\text { независимости) }\end{array}$ & 0,87 & 0,87 & 0,88 & 0,88 & 0,89 & 0,89 \\
\hline $\begin{array}{l}\text { 1.2. Коэффициент } \\
\text { обеспеченности } \\
\text { собственными оборотными } \\
\text { средствами }\end{array}$ & 0,61 & 0,61 & 0,72 & 0,76 & 0,81 & 0,87 \\
\hline $\begin{array}{l}\text { 1.3. Коэффициент покрытия } \\
\text { инвестиций }\end{array}$ & 0,97 & 0,94 & 0,93 & 0,91 & 0,89 & 0,87 \\
\hline
\end{tabular}




\begin{tabular}{|c|c|c|c|c|c|c|}
\hline \multicolumn{7}{|l|}{ 2. Ликвидность } \\
\hline $\begin{array}{l}\text { 2.1. Коэффициент текущей } \\
\text { ликвидности }\end{array}$ & 11,41 & 5,38 & 5,78 & 1,89 & 0 & 0 \\
\hline $\begin{array}{l}\text { 2.2. Коэффициент быстрой } \\
\text { ликвидности }\end{array}$ & 3,22 & 1,16 & 1,91 & 0,79 & 0,13 & 0 \\
\hline $\begin{array}{l}\text { 2.3. Коэффициент } \\
\text { абсолютной ликвидности }\end{array}$ & 0,24 & 0,02 & 0,9 & 1,05 & 1,38 & 1,71 \\
\hline \multicolumn{7}{|l|}{ 3. Рентабельность } \\
\hline 3.1. Рентабельность продаж & 0,25 & 0,20 & 0,26 & 0,25 & 0,25 & 0,26 \\
\hline 3.2. Рентабельность активов & 0,11 & 0,08 & 0,11 & 0,10 & 0,10 & 0,10 \\
\hline $\begin{array}{l}\text { 3.3. Рентабельность } \\
\text { собственного капитала }\end{array}$ & 0,13 & 0,09 & 0,13 & 0,12 & 0,12 & 0,12 \\
\hline
\end{tabular}

Достоверность прогноза по функции «Тенденция» высокая и составляет 96-100 \%. Исходя из данного прогноза, существенно снизится ликвидность предприятия. Важно знать, не грозит ли предприятию банкротство.

Диагностика банкротства - это такой вид финансового анализа, который нацелен на раннее выявление сбоев и упущений в деятельности предприятий, потенциально опасных согласно теории вероятности наступления банкротства. Предприятие, на котором хорошо поставлена аналитическая работа, способно раньше распознать надвигающийся кризис и оперативно отреагировать.

Уильям Бивер предложил свою систему показателей для оценки финансового состояния предприятия с целью диагностики банкротства. Бивер рекомендовал исследовать тренды показателей для диагностики банкротства. $[1$, c.67-70]. Система показателей Бивера и их значения для диагностики банкротства представлены в таблице 2.

Таблица 2

Система показателей У. Бивера для диагностики банкротства

\begin{tabular}{|l|l|c|c|c|c|}
\hline \multicolumn{1}{|c|}{ Показатели } & \multicolumn{1}{|c|}{ Расчет } & $\begin{array}{c}\text { Для } \\
\text { благополучных } \\
\text { показателей }\end{array}$ & $\begin{array}{c}\text { За 5 лет до } \\
\text { банкротства }\end{array}$ & $\begin{array}{c}\text { За 1 год до } \\
\text { банкротства }\end{array}$ & $\begin{array}{c}\text { Факт } \\
2019 \text { г. }\end{array}$ \\
\hline $\begin{array}{l}\text { Коэффициент } \\
\text { Бивера }\end{array}$ & $\begin{array}{l}\text { (Чистая прибыль } \\
\text { +Амортизация)/ } \\
\text { (Долгосрочные+ } \\
\text { Краткосрочные } \\
\text { обязательства) }\end{array}$ & $0,4-0,45$ & 0,17 & $-0,15$ & 1,685 \\
\hline $\begin{array}{l}\text { Рентабельность } \\
\text { активов, \% }\end{array}$ & $\begin{array}{l}\text { (Чистая } \\
\text { прибыль/Активы)*100 }\end{array}$ & $6-8$ & 4 & -22 & 11,13 \\
\hline
\end{tabular}




\begin{tabular}{|l|l|c|c|c|c|}
\hline $\begin{array}{l}\text { Финансовый } \\
\text { леверидж }\end{array}$ & $\begin{array}{l}\text { (Долгосрочные+Кратк } \\
\text { осрочные } \\
\text { обязательства)/Активы }\end{array}$ & $\begin{array}{c}\text { Меньше или } \\
\text { равно 37 }\end{array}$ & $\begin{array}{c}\text { Меньше или } \\
\text { равно 50 }\end{array}$ & $\begin{array}{c}\text { Меньше или } \\
\text { равно 80 }\end{array}$ & 0,115 \\
\hline $\begin{array}{l}\text { Коэффициент } \\
\text { покрытия } \\
\text { активов } \\
\text { чистым } \\
\text { оборотным } \\
\text { капиталом }\end{array}$ & $\begin{array}{l}\text { (Собственный } \\
\text { капитал-Внеоборотные } \\
\text { активы)/Активы }\end{array}$ & 0,4 & $\begin{array}{l}\text { Меньше или } \\
\text { равно 0,3 }\end{array}$ & $\begin{array}{c}\text { Приближен } \\
\text { но 0,06 }\end{array}$ & 0,3 \\
\hline $\begin{array}{l}\text { Коэффициент } \\
\text { покрытия }\end{array}$ & $\begin{array}{l}\text { Оборотные } \\
\text { активы/Краткосрочные } \\
\text { обязательства }\end{array}$ & $\begin{array}{c}\text { Меньше или } \\
\text { равно 3,2 }\end{array}$ & $\begin{array}{l}\text { Меньше или } \\
\text { равно 2 }\end{array}$ & $\begin{array}{l}\text { Меньше или } \\
\text { равно 1 }\end{array}$ & 9,01 \\
\hline
\end{tabular}

Значение коэффициента Бивера превышает 0,4, это говорит об удовлетворительной структуре баланса предприятия. Предприятию банкротство на ближайшие пять лет не грозит и оно является финансово устойчивым. Только коэффициент покрытия активов чистым оборотным капиталом имеет значение 0,3 , т.е. говорит о возможном банкротстве через 5 лет.

Одним из показателей вероятности банкротства организации является индекс Таффлера, который рассчитывается по следующей формуле:

$$
\mathrm{Z}-\text { счет }=0,53 \mathrm{X}_{1}+0,13 \mathrm{X}_{2}+0,18 \mathrm{X}_{3}+0,16 \mathrm{X}_{4} \text {. }
$$

По результатам расчетов для СХПК значение Z-счета по состоянию на 2019 год составило 1,783 (таблица 3).

Таблица 3

\section{Расчет индекса Таффлера}

\begin{tabular}{|c|c|c|c|c|}
\hline $\begin{array}{l}\text { Коэффи- } \\
\text { циент }\end{array}$ & Расчет & $\begin{array}{c}\text { Значение } \\
\text { за } 2019 \\
\text { год }\end{array}$ & Множитель & $\begin{array}{l}\text { Произ- } \\
\text { ведение }\end{array}$ \\
\hline $\mathrm{X} 1$ & $\begin{array}{l}\text { Соотношение прибыли от продаж и краткосрочных } \\
\text { обязательств }\end{array}$ & 1,022 & 0,53 & 0,542 \\
\hline $\mathrm{X} 2$ & $\begin{array}{l}\text { Соотношение оборотных активов и краткосрочных } \\
\text { обязательств }\end{array}$ & 9,018 & 0,13 & 1,172 \\
\hline $\mathrm{X} 3$ & $\begin{array}{l}\text { Соотношение краткосрочных обязательств и итога } \\
\text { баланса }\end{array}$ & 0,070 & 0,18 & 0,013 \\
\hline $\mathrm{X} 4$ & Соотношение выручки от продаж и итога баланса & 0,429 & 0,16 & 0,069 \\
\hline \multicolumn{4}{|c|}{ Z - счет Таффлера } & 1,783 \\
\hline
\end{tabular}

Предполагаемая вероятность банкротства в зависимости от значения Z счета Таффлера составляет:

При Z > 0,3 - вероятность банкротства низкая; 
При $0,2<\mathrm{Z}<0,3$ - состояние неопределённости;

При $Z<0,2$ - высокая вероятность банкротства.

Значение показателя 1,783 свидетельствует о низкой вероятности банкротства. По результатам финансового анализа различных элементов деятельности СХПК можно сказать, что предприятие финансово устойчиво, оно имеет достаточную рентабельность, которая способствует поддержанию платежеспособности на приемлемом уровне. Для сохранения финансового состояния предприятия на достигнутом уровне следует грамотно вести финансово-хозяйственную деятельность.

Тенденция снижения рентабельности к 2021 году требует от руководства предприятия реализации комплекса мер по повышению эффективности производства. Рентабельность продаж зависит от множества факторов. В сельскохозяйственном предприятии, как правило, реализуется зерно, молоко. Бочкарев М.В. отмечает, что рентабельность реализации зерна напрямую связана с эффективными рынками сбыта [2, с.43].

Различные культуры существенно дифференцированы по уроню прибыли, полученной с 1 га. Ряд авторов отмечают, что наиболее рентабельными являются такие виды продукции, как картофель [3, с.33], овощи $[4, \mathrm{c} .28]$. Поэтому от грамотного, экономически обоснованного набора культур также зависит прибыль и рентабельность.

Высокая эффективность производства связана и с рациональным использованием трудовых ресурсов [6, с.56].

Финансовое состояние предприятия зависит от ряда факторов, своевременный анализ показателей позволяет оценить финансовую устойчивость, ликвидность и рентабельность, т.е. возможности для развития.

\section{Список литературы}

1. Анализ финансовой отчетности : учебное пособие / авторсоставитель М. Ф. Тяпкина. - Иркутск: Иркутский ГАУ, 2019. - 117 с. Текст : электронный // Лань : электронно-библиотечная система. - URL: https://e.lanbook.com/book/133386.

2. Бочкарев, М.В. Управление сбытом зерна в сельскохозяйственных предприятиях/ М.В.Бочкарев, С.Н.Навдаева // Влияние цифровой экономики на развитие аграрного сектора России. Материалы Всероссийской научнопрактической конференции с международным участием студентов и молодых ученых. -2018. -С. 41-44 
3. Навдаева, С.Н. Экономическая эффективность производства картофеля в сельскохозяйственных организациях Нижегородской области / C.Н. Навдаева, Е.А. Гунина // Экономика сельскохозяйственных и перерабатывающих предприятий. -2018. -№ 1.- С. 29-34

4. Навдаева, С.Н. Тенденции развития растениеводства в Нижегородской области / С.Н.Навдаева, Д.С. Колобов, М.Е.Озеряник, С.И. Олонина // Экономика сельскохозяйственных и перерабатывающих предприятий.-2020.-№ 11.-с. 25-29

5. Навдаева, С.Н. Экономико-статистический анализ показателей деятельности сельскохозяйственных предприятий: учебное пособие / С.Н. Навдаева, Т.Д. Дудогло; ФГБОУ ВО Нижегородская ГСХА Н.Новгород, 2020. - $100 \mathrm{c}$.

6. Навдаева, С.Н. Трудовые ресурсы сельских территорий Нижегородской области / С.Н.Навдаева, М.Е.Озеряник // Экономика сельскохозяйственных и перерабатывающих предприятий.-2021.-№ 2.-с. 55-60

(C) Ю.Д.Колесова, С.Н.Навдаева, 2021 